\title{
Exploration on the Talents Cultivation of Statistics Based on Social Needs \\ Yushuang Chen ${ }^{*}$ and Xintong Zhang \\ Changchun University of Finance and Economic, China \\ *Corresponding author: Yushuang Chen, Mster’s degree, shuang_youyou@126.com
}

\begin{abstract}
In order to adapt to the new demands for social development brought by the era of big data, the core task of talents cultivation for statistics has become that training statistical personnel with the applied statistics as the main, the theoretical statistics as an auxiliary. Through the analysis of the current situation of the social needs for statistical professionals, we put forward the professional ability and quality that statisticians should possess, and how to guide the students to improve their ability of independent observation and thinking, to meet the social needs better.
\end{abstract}

Key words: social needs; statistical personnel; talents cultivation; practice teaching

With the change of times, statistical work is constantly changing and expanding, including simple accounting summary, index system construction, statistical model theory, data collection and collation, empirical analysis and many other aspects. Gradually, statistics has been transformed from economic social service to the basic elements of socioeconomic development discipline, and becomes an important force for socioeconomic development. In particular, due to the arrival of the era of big data, highlighting the importance of data information brings the spring of statistics, and social demand for statistical personnel is growing.

\section{Analysis on the current situation of social needs of statistical personnel}

Since the expansion of higher education in the late 20th century, China's higher education has realized the transition from elite education to mass education, millions of college graduates flocking to the community every year, however, the feedback from the talent market information shows that the proportion of talent in line with the needs of the community is not satisfactory. The reasons for this phenomenon are in many aspects, the two most important of which are the disconnection between the 
demand of social talents and the cultivation of talents in colleges and universities and the dissociation between the employment needs of students and the setting of the curriculum system in colleges and universities. Through collecting and summarizing the information from talent recruitment website and statistics graduates' feedback, it is found that job requirements for professional statistical personnel are mainly in the following aspects.

\subsection{Socioeconomic survey}

Socioeconomic survey mainly aims at data collection, sorting and description of the state of socioeconomic phenomena, exploring the inherent law and essence of socioeconomic phenomena. In general, the investigation of social phenomena and macroeconomic phenomena is focused on the various departments of the state, such as the ongoing agricultural census and other comprehensive investigations that need professional statisticians to participate and organize from the program design to the specific implementation of the data summary, as well as sampling survey for a specific problem, residents happiness index, etc. the investigation of the micro economic phenomenon is concentrated in the enterprises and institutions, such as the consumer's satisfaction with the products.

\subsection{Quantitative analysis and forecast}

Quantitative analysis and prediction mainly build statistical modeling according to the collected data, dig the running rules of the data and further give a certain grasp of the forecast, finally provide guidance for decision-making. In fact, it is the combination of past and present to infer the state in future, finding the factors affecting the change, then further improve the good aspects that may occur in the future and inhibit the bad aspects according to the factors that affect the changes. For example, through the seasonal index estimates, you can learn that the product sales cycle changes that anti season promotions and other marketing tools are taken in the off-season sales to reduce the loss.

\subsection{Others}

The above two kinds of work content could be engage by talents who have only learned systematically the professional knowledge of statistics, many jobs are not only limited to the statistics, such as information management, consulting, etc. However, 
most of these positions require candidates to have the basic quality of professional logical thinking, that is to say, the most important aspect of Statistics are "induction" and "grouping", statistical professionals in the learning process have developed a habit of classification, summed up strong ability, and solved problems with clear ideas.

\section{The basic ability of statistical personnel}

In order to quickly enter the working state, better integrate into society and reduce the time cycle in the study of work, university training should be with the applied statistics as the main and the theoretical statistics as an auxiliary, guiding students to improve their ability to observe and think independently of social and economic phenomena and to analyze and solve problems by means of statistical techniques, cultivating students' practical ability, also leading students to establish a correct outlook on world, life and values, a professional and professional view. ${ }^{1}$ Finally, a statistical person enhances the overall quality and enhances the competitive advantage with serious work attitude, unity and coordination of operation mode. In this way, students can also do a good job in socio-economic investigation, quantitative analysis and forecasting work.

\subsection{Cutting accurately the key points}

Faced with a practical problem to be solved in the work, we are always unlike the final exam in the school, four options are given to choose the correct one, or which index is explicitly required. For example, analysis of population development needs to know thoroughly which point of view, choice of indicators and collection of data before a comprehensive and accurate display of population development. So this requires the ability of statistical personnel to find the point of entry, which is commonly referred to as the ability to find, analyze and solve problems.

\subsection{Using skillfully statistical techniques}

The most important role of statistics is to use a variety of methods to dig the data characteristics and data law, and then reveal the inherent nature of the development of things. In order to achieve deep mining, we need to use a variety of statistical models as tools, including regression analysis, factor analysis, input output method, etc. The information development and big data era further ask application of statistical analysis 
software, in addition to excel, Eviews, SPSS and other software to click operation as the main, SAS, R, Stata, Pathon and other programming and programming software has become increasingly important, even specialized data analysis software needs to be further mastered.

\subsection{Having professional qualities and team awareness}

It is the most basic professional quality of statistics to emphasize "decision based on data” and not to be tampered because of inconsistent with the analysis of the data rules and expectations. At the same time, statistics require us to work together and complete the investigation and analysis, therefore statisticians must have a sense of teamwork.

\section{The training way of statistical personnel to meet the needs of society}

Higher education undertakes the important task of training high-level talents, developing science and technology culture, and promoting socialist modernization. Therefore, colleges and universities in the statistical professional construction, must adapt to the economic and social development of the new initiative, basing on society and into place, planning scientifically how to establish teaching orientation, innovating educational ideas and teaching methods,improving adaptability of students majoring in statistics to serve economic society, promoting the interactive development between students and the demand of knowledge economy society. ${ }^{2}$

\subsection{Innovate training model, highlight the ability training}

For a long time, colleges and universities in the training of personnel choose the traditional "ivory tower" education as the main. Therefore, even if the ministry of education has proposed the transformation of colleges and universities, the application of the University to revise the personnel training program and increase the proportion of practice hours, there are still such as the practice of "sheep" phenomenon, in other words, let the students find their own internship units and come back to write a report, which cannot realize to know more about society and exercise the abilities.

From the perspective of social demand for talents, colleges and universities must change the traditional "ivory tower" talent training model in the real sense. Actively contact the enterprise, government departments at all levels, especially the Bureau of statistics, investigation Brigade and other units to carry out all aspects of cooperation 
to achieve mutual benefit. On the one hand, have an expert with wealth of practical experience in the introduction of social statistics to teach related courses in the school; on the other hand, allow students to real work in related internship; besides, students can also participate in the horizontal project, studying the industry background, using legitimately statistical expertise and data analysis skills, to solve practical problems for enterprises and institute cooperation of industry, university and research. In turn, enhance the students' practical ability and innovation ability, train in line with the needs of social and economic development of high-quality professional statistical personnel.

\subsection{Carry out the second classroom and enhance professional interest}

In the practice of teaching in colleges and universities, the internal and external practice is the most commonly used way to verify and consolidate the theoretical knowledge of classroom teaching and learning the necessary knowledge and skills.In addition, it should also actively carry out the second classroom, the establishment of market research associations, statistical modeling community and other professional communities to arouse students' interest, use after-school life for better service for professional knowledge learning. The society is not only limited to recruit students of statistics, but also should be combined with other professional expertise, extensive exchanges and expand knowledge.

\subsection{Organize the discipline competition, enhance the comprehensive quality}

There are domestic statistical discipline contests in mathematical modeling, statistical modeling contest, market research competition, etc., the characteristics of which are practical application and team competition. Competition is not a problem, but to solve a problem, whose answer is not unique, whose entry point is uncertain. In order to better finish, students who participate in competition should integrate professional knowledge and develop relevant knowledge, meanwhile unity and cooperation to adapt to complex analysis and larger workload. Professional discipline competition can be achieved to promote the development of competition, and improve the overall quality of students from the ability to collect data, the use of professional knowledge, personal ability, teamwork and other aspects. 


\section{Conclusions}

The purpose of learning is to serve the society. A student of statistics should have some abilities such as socioeconomic survey, quantitative analysis and forecast and so on. In order to cultivate the abilities mentioned above, we need to attach importance to practice teaching and strengthen the construction of practice teaching in a university.

\section{Acknowledgements}

Teaching reform and construction project of Changchun University of Finance and Economics: Research and Practice on the reform of teaching and examination methods in private colleges and Universities Based on practice and innovation ability

\section{References:}

1. X.M.Guo, Highlight the "three docking" to enhance the ability of local colleges and universities to serve the social development, Journal of Hunan university of science and engineering, 2012 (12).

2. M.N. Ma, G.R. Li, X.Y. Ma, The reform and practice of the construction of Statistics Specialty in finance and Economics Colleges: Based on the perspective of the training model of statistical talents, Statistics and consulting, 2012(6): 38-40. 